\title{
Disease associated with Yersinia ruckeri infection in Cyprinus carpio in a common carp farm in Germany
}

\author{
K. Böttcher ${ }^{1}$, R. Richter ${ }^{2}$, V. Bulla ${ }^{3}$ \\ ${ }^{1}$ Fischgesundheitsdienst, Sächsische Tierseuchenkasse, ${ }^{2}$ Teichwirtschaft Kreba, ${ }^{3}$ Landesuntersuchungsanstalt für das Gesundheits- und Veterinärwesen \\ Sachsen \\ Keywords: Yersinia ruckeri, Cyprinus carpio, common carp \\ https://doi.org/10.48045/001c.28220
}

Bulletin of the European Association of Fish Pathologists

Vol. 41, Issue 3, 2021

\begin{abstract}
A case of skin alterations and mortalities associated with Yersinia ruckeri in two summer old common carp after over-wintering in a hibernation pond is described in the present work. The disease was characterised mainly by erosions around the orbital area of the fish. The bacterium was cultivated on Columbia agar and identified by MALDI-TOF, by biochemical characteristics and by sequencing $16 \mathrm{~s}$ rDNA. Parasitological and virological examinations revealed no relevant findings. Usually the pathogen is associated with salmonids, which were not present on the farm investigated in this study.
\end{abstract}

In April 2018 skin lesions and mortalities were observed in two summer old common carp (Cyprinus carpio) while removing them from an over-wintering hibernation pond. The farm involved is situated in the lowlands in Eastern Saxony in a biosphere reserve "Heide- und Teichlandschaft" "'heathlands and ponds"), which means that there are many carp farms in the area. The farm consists of 59 ponds, which together covers around 407 hectares of aquacultural area. A small river supplies the farm with water. Upstream there are other carp farms and a great and shallow artificial lake of more than 700 hectares with different wild fish species, but which is not suitable for salmonids. The farm is specialised in production of common carp and some secondary fish e.g. grass carp (Ctenopharygodon idella) and tench (Tinca tinca).

Fish in most hibernation ponds were not diseased. Only fish in one particular pond with a size of 1.92 hectare were affected. The population in that pond consisted of about 17,000 individuals weighing $585 \mathrm{~g}$ on average. Overwintering mortalities (October 2017 - April 2018) in this pond were $3.6 \%$, which is well below the normal expected. This indicates that fish had been in a good health state despite a high stocking density of 5.2 tons/ hectare in the hibernation pond. Within two days after harvest about 450 animals died, equating to $2.7 \%$ in a $48 \mathrm{~h}$ period. Thereafter, animals were put in production ponds with low densities of $136-251 \mathrm{~kg} /$ hectare and optimal environmental conditions. No treatment was carried out. Percentage of mortalities from April to October 2018 came to $9.0 \%$, which is below average, and which gave no indication of any underlying health problems. In autumn 2018, clinically healthy table carp were harvested.

The water temperature at the day of harvest in April was $11{ }^{\circ} \mathrm{C}$. When fish were examined by the fish health service, nearly $100 \%$ of the animals were suffering from skin alterations. In most individuals the orbital area was affected 


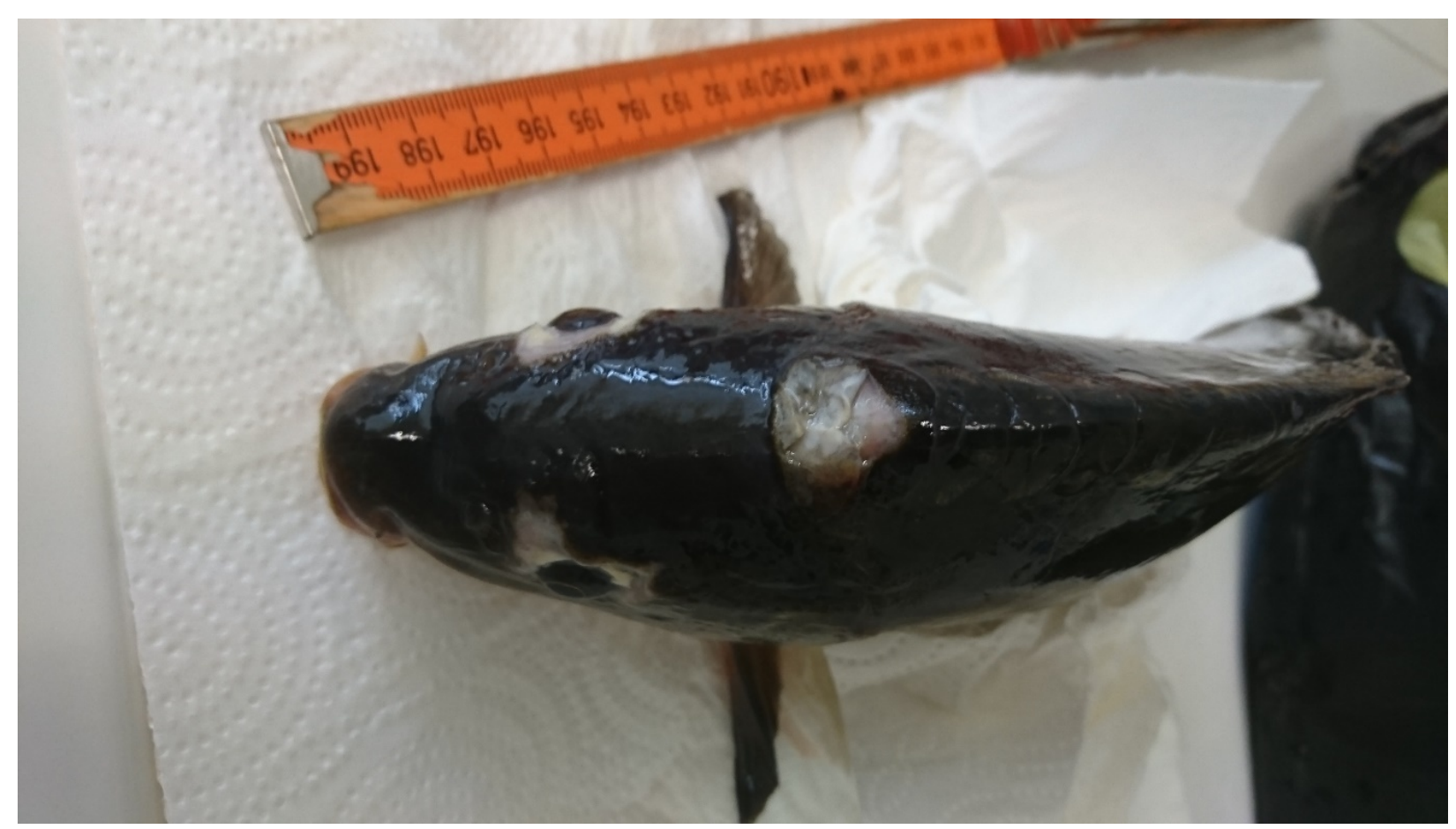

Figure 1. Specimen of Cyprinus carpio infected with Yersinia ruckeri: erosion and necrosis of the skin in the head region, in particular around the eyes.

with erosions and necrosis of the skin, leading to the appearance of bony structures (Figure 1). Similar alterations were found in many fish around the head, in particular surrounding the mouth. Some fish also showed carperythrodermatitis-like ulcers on their caudal peduncle or at the base of their fins. In some cases, extensive reddening and swelling were located on the lateral abdomen (Figure 2).

Gills appeared macroscopically regular. Scrapes of skin and gills were examined microscopically. Findings included the occasional incidence of Trichodina sp., Gyrodactylus sp. and Saprolegnia sp. (the latter only in altered regions) in the skin scrapes, as well as low to moderate levels of parasites in the gill samples (Ichthyobodo sp., Chilodonella sp., Trichodina sp.). Necropsy revealed a moderate nutritional condition in accordance with the season and little intestinal contents. Internal organs of a few individuals seemed to be glassy and fused together. Apart from this no relevant diagnostic findings could be detected.

Further investigations were conducted at Landesuntersuchungsanstalt für das Gesundheits- und Veterinärwesen Sachsen (State research laboratory). Tissue samples of gills, gills and kidneys, and hearts, spleens and kidneys were examined for carp oedema virus, koi herpesvirus and spring viraemia of carp, respectively, by polymerase chain reaction, the results of which were all negative. As an accredited laboratory Landesuntersuchungsanstalt used appropriate positive and negative controls for these assays. A pool of skin samples and another pool of inner organs (heart, spleen, kidney) from five 


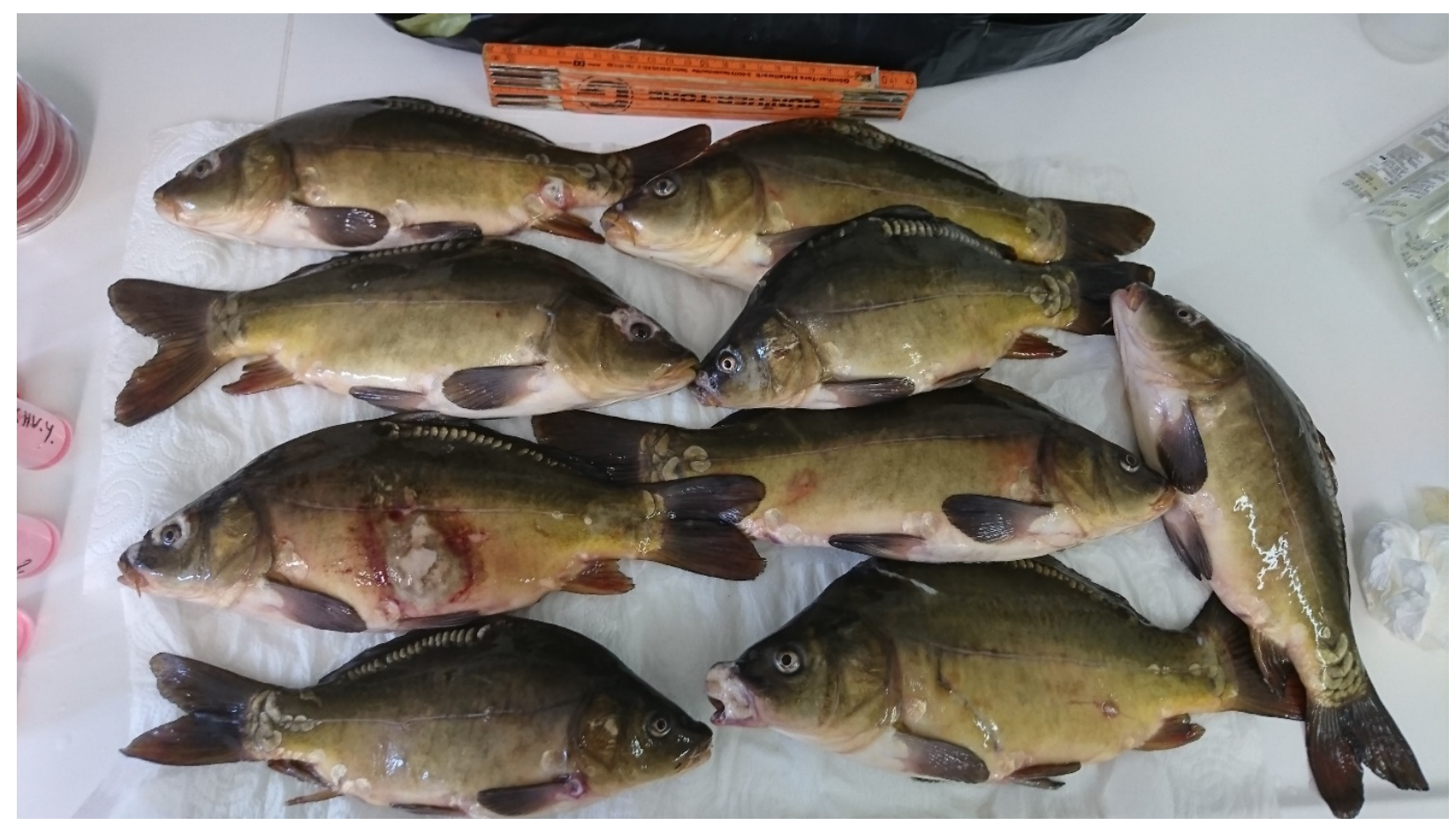

Figure 2. Clinical signs in Cyprinus carpio infected with Yersinia ruckeri: skin alterations primarily around the orbital region and the mouth, in addition carp-erythrodermatitis-like ulcers on caudal peduncle or fin base, extensive reddening and swelling on lateral abdomen.

individuals were also examined by electron microscopy (negative contrast), with no virus particles found in the samples. Histology was not performed on affected fish.

Swab samples from affected skin, liver, kidney and spleen of four severely affected fish were streaked for bacteriology onto Columbia agar supplemented with $7 \%$ sheep's blood and incubated for two days at $22-26^{\circ} \mathrm{C}$. Colonies were sub-cultured in the same way. Culture time and incubation temperature were performed according to in-house protocols. Landesuntersuchungsanstalt is a routine diagnostic laboratory, therefore standardisation of procedures with regards to incubation of bacterial cultures is required even though some fish are kept at other temperatures.

Skin samples from three of the fish produced mixed cultures of Aeromonas veronii biovar sobria and Yersinia ruckeri, with low to moderate amounts of colonies obtained, while swabs of their internal organs produced no bacterial growth. Pure cultures of Yersinia ruckeri were isolated from one fish with high amounts of colonies obtained from skin as well as all internal organs sampled (Figure 3). Identification of Yersinia ruckeri was conducted using MALDITOF (VITEK ${ }^{\circledR M S}$, bioMerieux) with a high confidence level of $99.9 \%$. In addition, biochemical characterisation of the bacterium was performed using VITEK ${ }^{\circledR 2}$ Compact, bioMerieux with GN-ID-card (product number 21341) according to the manufacturer's recommendations. Yersinia ruckeri was confirmed with $93 \%$ probability, which is a very good level of identification. Motility was not tested. Further verification of the results was performed by 


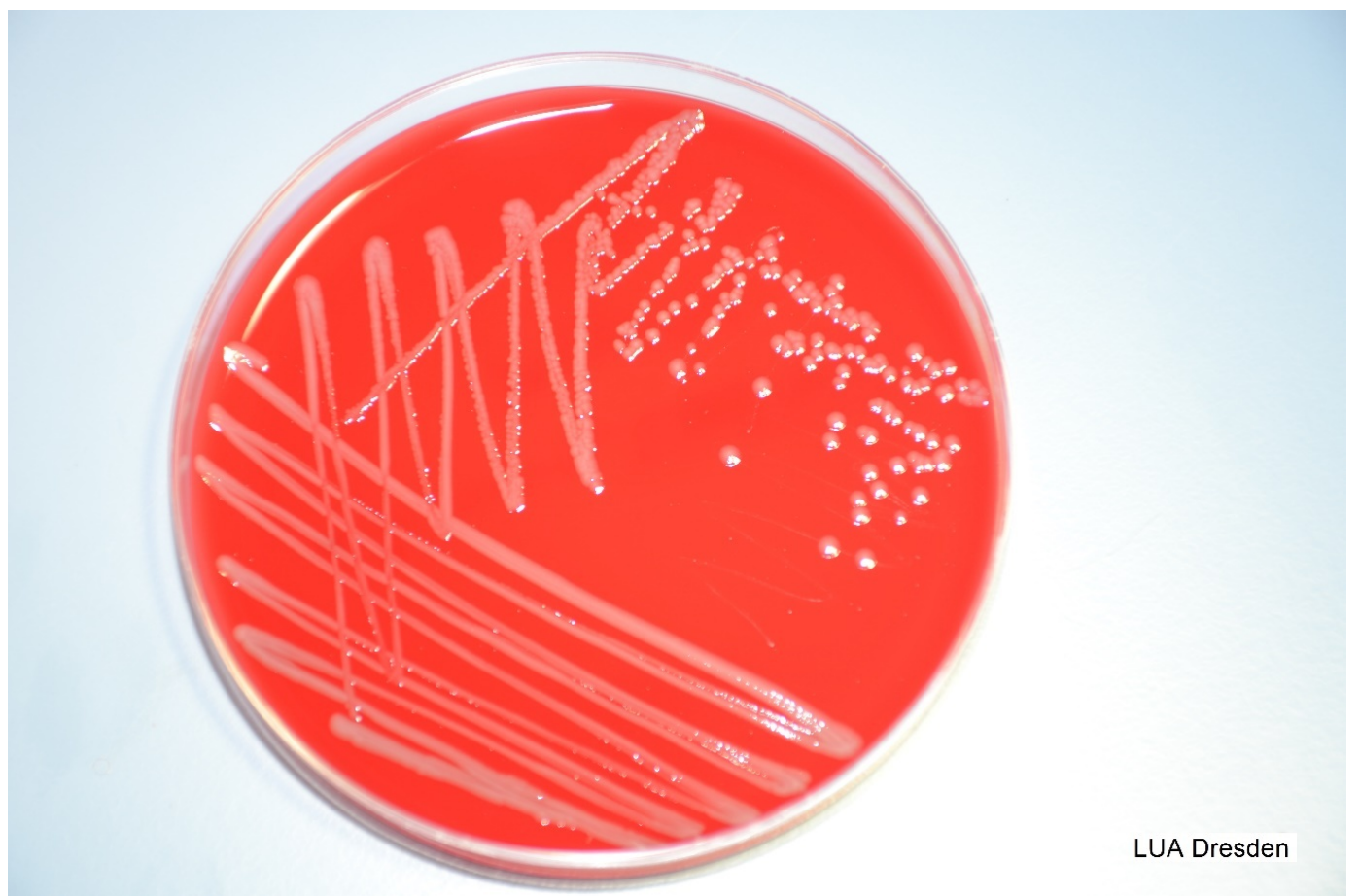

Figure 3. Pure culture of Yersinia ruckeri on Columbia agar supplemented with $7 \%$ sheep's blood.

molecular means (Sanger sequencing and comparison of analysed 16s rDNA with IDNS ${ }^{\mathrm{TM}}$ Integrated Database Network System) showing sequence homology of $100 \%$ with the entry for Yersinia ruckeri (CP0231848). Sequence was not deposited at NCBI and no phylogenetic tree is available, because of routine diagnostic work at the laboratory. No experimental challenges were performed to examine the virulence of the bacterium.

The bacterium Yersinia ruckeri is the causative agent of enteric redmouth disease (ERM) (Bruno and Poppe 1996). ERM was first described in rainbow trout (Oncorbynchus mykiss) in Idaho, USA (Rucker 1966), but nowadays the disease can be found in several countries and continents (Mattes 2004; Eissa et al. 2008). Clinical ERM is typically associated with salmonids (Bullock and Sniezko 1975; Austin and Austin 2012). Transmission tends to occur from fish to fish, and also from contaminated water, equipment and tanks (Mattes 2004). Both salmonid and non-salmonid carriers without symptoms are responsible for spreading the bacterium (Bruno and Poppe 1996). An outbreak of ERM was reported in common carp in southern Russia (Kazarnikova et al. 2017, 2019) one season after the ponds contained clinically healthy rainbow trout. In the present study we could not establish any link between the affected carp and a salmonid origin of the disease. Salmonids were never kept on the farm itself nor in the surrounding region, mainly because the water supply and temperature range in the lowlands is unsuitable. Yersinia ruckeri has never been isolated before or after on the farm or in wild fish living in the region of the farm. Yersina ruckeri has been isolated in large numbers from invertebrates like crayfish, and from birds and mammals, notably muskrat 
and otter (Stevenson and Daly 1982; Collins, Foster, and Ross 1996). In the biosphere reserve where the farm is situated, many of these species are native. To our knowledge these animals have not yet been checked for the presence of Yersinia ruckeri. Therefore, the origin of the pathogen remains unexplained.

The main symptoms of Yersinia ruckeri infection in salmonids are described as reddening of the mouth and throat due to submucosal hyperaemia, congestion, ulceration and haemorrhage of the oral cavity, cutaneous petechiae, darkening of the skin, exophthalmia, petechial haemorrhage of the musculature, large intestine, liver and caeca, enteritis (Bruno and Poppe 1996). Fuhrmann, Böhm, and Schlotfeldt (1984) found Y. ruckeri in carp without any symptoms and in eel (Anguilla anguilla) with skin lesions in the head region. A few authors have reported non-salmonid fish expressing symptoms typical for ERM. Eissa et al. (2008) documented characteristic symptoms in Nile tilapia (Oreochromis niloticus) and Manna et al. (2003) in experimentally infected Indian Major Carp (Labeo robita, Catla catla and Cirrbina mrigala). Kazarnikova et al. $(2017,2019)$ described a case of mortalities in carp due to Yersinia ruckeri infection. External symptoms appeared non-specific, such as petechial haemorrhages on the ventral side of the body, manifestation of Saprolegnia sp. and anaemic gills, while internal alterations resembled ERM with haemorrhages on the serous membrane of the abdominal cavity and swim bladder and also hyperaemia of the posterior intestine. In the present case infected common carp showed neither reddening of the oral cavity nor enteritis or petechial haemorrhage in muscle or internal organs. The affected fish showed skin erosions mainly in the head region, especially around the orbital rings as well as reddening of the skin. Similar alterations were mentioned by Danley, Goodwin, and Killian (1999) in channel catfish (Ictalurus punctatus) infected by Yersinia ruckeri. The main symptoms in that disease event were extraordinary haemorrhagic rings around the eyes. These symptoms could conceivably be considered as a preliminary stage of the necrotic erosions observed in the present case in carp.

In salmonids susceptible to the bacterium, outbreaks tend to occur mainly at water temperatures above $10{ }^{\circ} \mathrm{C}$ with low-levels of mortalities resulting, but which increase significantly when fish become stressed (Bruno and Poppe 1996). This corresponds to our observations with water temperatures of $11^{\circ} \mathrm{C}$, with increasing mortalities occurring during harvest while fish were stressed. Increasing water temperature to $15-18{ }^{\circ} \mathrm{C}$ also leads to severity peaks in mortalities in salmonids (Austin and Austin 2012). In the presented case the water temperature was very stable at about $4{ }^{\circ} \mathrm{C}$ for eight weeks and increased rapidly to $11^{\circ} \mathrm{C}$ in a few days before harvest because of the start of a heat wave. This could have been a promoting factor for bacterial growth and the outbreak of the disease. 
In conclusion, the case presented here is unusual because of the presence of the identified pathogen Yersinia ruckeri in common carp in the absence of salmonids or other conceivable reservoirs of the pathogen in the location of the fish farm, and also the peculiar symptomatology of the disease. As a representative of the Enterobacteriaceae, Yersinia ruckeri is expected to grow in the internal organs of affected fish, but in this case the affected regions and bacterial growth were mainly on the outside of the fish and Yersinia ruckeri was rarely found in internal organs.

Submitted: April 30, 2021 GMT, Accepted: June 03, 2021 GMT

This is an open-access article distributed under the terms of the Creative Commons Attribution 4.0 International License (CCBY-4.0). View this license's legal deed at http://creativecommons.org/licenses/ by/4.0 and legal code at http://creativecommons.org/licenses/by/4.0/legalcode for more information. 


\section{REFERENCES}

Austin, B., and D.A. Austin. 2012. "Yersinia Ruckeri." In Bacterial Fish Pathogens, 267-78.

Dordrecht: Springer.

Bruno, D.W., and T.T. Poppe. 1996. “Enteric Redmouth.” In A Colour Atlas of Salmonid Diseases, 43-44. London: Academic Press.

Bullock, G.L., and S.F. Sniezko. 1975. "Hagerman Redmouth, a Disease of Salmonids Caused by a Member of the Enterobacteriaceae." United States Department of the Interior, Fish and Wildlife Service, Fish Disease Leaflet 42: 1-5.

Collins, R. O., G. Foster, and H. M. Ross. 1996. "Isolation of Yersinia Ruckeri from an Otter and Salmonid Fish from Adjacent Freshwater Catchments.” Veterinary Record 139 (7): 169-169. https://doi.org/10.1136/vr.139.7.169.

Danley, M.L., A.E. Goodwin, and H.S. Killian. 1999. "Epizootics in Farm-Raised Channel Catfish, Ictalurus Punctatus (Rafinesque), Caused by the Enteric Redmouth Bacterium Yersinia Ruckeri." Journal of Fish Diseases 22 (6): 451-56.

Eissa, A.E., M. Moustafa, M. Abdelaziz, and N.A. Ezzeldeen. 2008. "Yersinia Ruckeri Infection in Cultured Nile Tilapia, Oreochromis Niloticus, at a Semi-Intensive Fish Farm in Lower Egypt." African Journal of Aquatic Science 33 (3): 283-86. https://doi.org/10.2989/ajas.2008.33.3.13.625.

Fuhrmann, H., K.H. Böhm, and H.J. Schlotfeldt. 1984. "On the Importance of Enteric Bacteria in the Bacteriology of Freshwater Fish.” Bulletin of the European Association of Fish Pathologists 4 (3): $42-46$.

Kazarnikova, A.V., H.V. Shestakovskaya, A.V. Trishina, M. Galeotti, and M. Manzano. 2017. "The First Isolation of Yersinia Ruckeri from Carp Cyprinus Carpio in Ponds of Southern Russia." Science in the South of Russia 13 (1): 102-14. https://doi.org/10.23885/ 2500-0640-2017-13-1-102-114.

Kazarnikova, A.V., A. Trishina, M. Galeotti, M. Manzano, N. Abrosimova, and A. Ermakov. 2019. "Detecting Yersinia Ruckeri on the Death of Carp (Cyprinus Carpio) Farmed in Southern Russia." IOP Conference Series: Earth and Environmental Science 403 (1): 012039. https://doi.org/10.1088/ $1755-1315 / 403 / 1 / 012039$.

Manna, S.K., S. Samanta, M.K. Das, and S.S. Mishra. 2003. "An Outbreak of Yersinia Ruckeri Septicaemia in Indian Major Carps." Journal of the Inland Fisheries Society of India 35 (2): 28-31.

Mattes, M. 2004. "Untersuchungen zur Empfänglichkeit zweier Regenbogenforellenstämme gegenüber Tetracapsuloides bryosalmonae, Yersinia ruckeri und dem Viralen Hämorrhagischen Septikämie-Virus.” Thesis/ Dissertation, Ludwig-Maximilians-Universität München.

Rucker, R.R. 1966. "Redmouth Disease of Rainbow Trout (Salmo Gairdneri).” Bulletin - Office International Des Epizooties 65: 825-30.

Stevenson, R. M. W., and J. G. Daly. 1982. "Biochemical and Serological Characteristics of Ontario Isolates of Yersinia Ruckeri." Canadian Journal of Fisheries and Aquatic Science 39 (6): 870-76. https://doi.org/10.1139/f82-118. 